Sādhanā Vol. 36, Part 1, February 2011, pp. 17-34. (C Indian Academy of Sciences

\title{
Seismic strengthening of RC structures with exterior shear walls
}

\author{
HASAN KAPLAN $^{1,2}$, SALIH YILMAZ ${ }^{1, *}$, NIHAT CETINKAYA ${ }^{3}$ \\ and ERGIN ATIMTAY ${ }^{4}$
}

${ }^{1}$ Department of Civil Engineering, Pamukkale University, Denizli, Turkey 20070

${ }^{2}$ Department of Civil Engineering, Epoka University, Tirana, Albania

${ }^{3}$ Department of Civil Engineering, Inonu University, Malatya, Turkey 44280

${ }^{4}$ Department of Civil Engineering, Middle East Technical University, Ankara, Turkey 06531

e-mail: hkaplan@pau.edu.tr; syilmaz@pau.edu.tr; ncetinkaya@inonu.edu.tr; a3702@metu.edu.tr

MS received 25 September 2009; revised 2 June 2010; accepted 9 August 2010

\begin{abstract}
Vulnerable buildings and their rehabilitation are important problems for earthquake regions. In recent decades the goal of building rehabilitation and strengthening has gained research attention and numerous techniques have been developed to achieve this. However, most of these strengthening techniques disturb the occupants, who must vacate the building during renovation. In this study, a new strengthening alternative for RC structures, namely exterior shear walls, has been experimentally investigated under reversed cyclic loading. Using the proposed technique, it is possible to strengthen structures without disturbing their users or vacating the building during renovation. In this technique, shear walls are installed in parallel to the building's exterior sides. It has been observed that the usage of exterior shear walls considerably improve the capacity and sway stiffness of RC structures. The experimental results have also been compared and found to be in agreement with the numerical solutions. Post attached exterior shear walls behaved as a monolithic member of the structure. Design considerations for the exterior shear wall-strengthened buildings have also been discussed in the paper.
\end{abstract}

Keywords. Seismic engineering; rehabilitation; concrete structures; exterior shear wall; earthquake damage.

\section{Introduction}

Many reinforced concrete (RC) buildings have either collapsed or experienced different levels of damage during past earthquakes. Many investigations have been carried out on buildings that were damaged or ruined by earthquakes. Low-quality concrete, poor confinement of the

*For correspondence 
end regions, weak column-strong beam behaviour, short column behaviour, inadequate splice lengths and improper hooks of the stirrups were some of the important structural deficiencies (Yakut et al 2005). Most of those buildings were constructed before the introduction of modern building codes. They usually cannot provide the required ductility, lateral stiffness and strength, which are definitely lower than the limits imposed by the modern building codes. Due to low lateral stiffness and strength, vulnerable structures are subjected to large displacement demands, which cannot be met adequately as they have low ductility.

Nowadays, most of the strengthening strategies are based on global strengthening schemes (Moehle 2000) as per which the structure is usually strengthened for limiting lateral displacements in order to compensate the low ductility (Sonuvar et al 2004). In these schemes, global behaviour of the system is transformed. Another approach is modification of deficient elements to increase ductility so that the deficient elements will not reach their limit state conditions when subjected to design loads (Moehle 2000). However, the latter strategy is more expensive and harder to implement in cases of many deficient elements which is the reason that the global strengthening methods have been more popular than element strengthening.

Among the global strengthening methods, addition of RC infill is the most popular one. Many researchers have focused on this subject and found that installation of RC infills greatly improve lateral load capacity and stiffness of the structure (Jirsa \& Kreger 1989; Altin et al 1992; Albanesi et al 2006). Even in cases of application to damaged buildings, the infill method yields satisfactory results (Sonuvar et al 2004; Canbay et al 2003). In some other researches, the use of wing walls, attached to two sides of columns was investigated. The systems strengthened with wing walls exhibited ductile behaviour (Higashi et al 1982; Bush et al 1991).

Steel bracing for RC frames has also been used to reduce drift demands. Bracing can either be implemented inside the frame (Masri \& Goel 1996) or applied from outside the system (Bush et al 1991). Post-tensioned steel bracing is also an efficient alternative for vulnerable framed buildings (Gilmore et al 1996) and it compensates structural irregularities. Experimental results for another alternative, knee bracing with shear links replaced with masonry infills, lead to improvement in energy absorption capacity (Perera et al 2004; Ohmura et al 2006).

Although, each of these methods satisfactorily increased the strength and stiffness, all of them with the exception of external steel bracing require construction work inside the building, which means disturbance of users and results in the buildings being out of service. Consequently, research efforts in this field have shifted their focus to new methods that could overcome this difficulty. The precast panel infill method, which causes less disturbance for the building occupants, has been investigated and found to be an efficient solution for strengthening of existing structures (Frosch et al 1996; Baran 2005). Despite causing some architectural problems, some other researchers (Kaltakci et al 2008) perpendicularly installed RC shear walls outside the building. This kind of shear walls were also applied to precast skeletal structures with an external diaphragm at the roof level (Kaplan et al 2009). This method has increased the lateral load capacity and strength of the structure as well. It should also be noted that the method requires the sides of the buildings to be unobstructed for installation of new shear walls.

The literature review presents numerous strengthening techniques. However, most of them require long-term construction works inside the building, rendering the building out of service for that period of time. On the other hand, external strengthening techniques offer advantages with respect to cost and ease of construction (Sucuoglu et al 2006). This study investigates the performance of exterior RC shear walls (ESW) that are placed parallel to the building's sides.

In reality, installing a shear wall to a structural system will surely improve the seismic capacity of the structure. The main concern is whether the design methods for the connection of old and new elements can satisfy codes. To make it clear, an experimental program was carried 


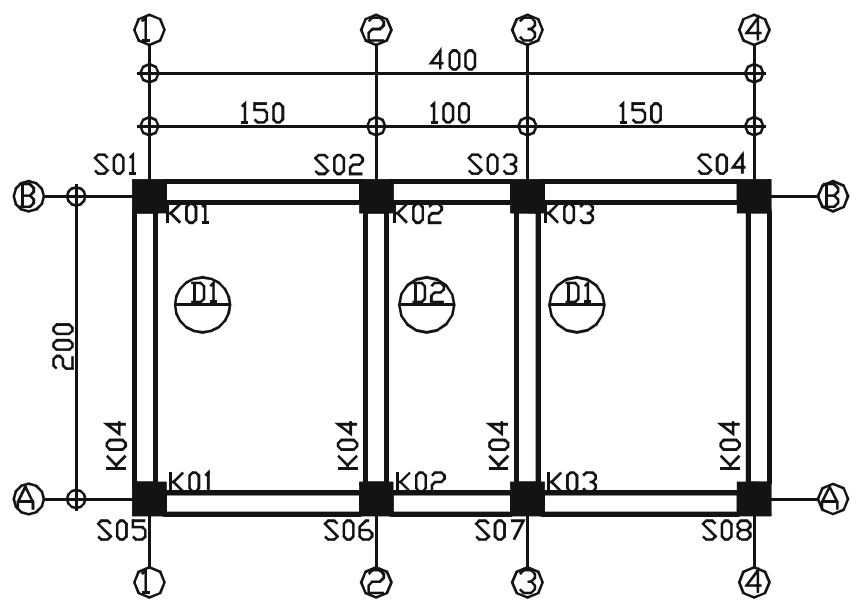

Figure 1. Plan view of reference model (dimensions: $\mathrm{cm}$ ).

out on two-storey three-dimensional RC models. The program includes a reference model and a strengthened model. Additionally, numerical solutions are presented and compared with the results of the experiments.

\section{Experimental study}

\subsection{Models}

The experimental program included two-storey RC models, which were built in one-third scale, three-bay in direction of loading and one-bay in the other direction. One of the models was the reference model (RM); the other was the strengthened model (SM). The same construction conditions, materials and curing methods were used in both models.

Geometrical dimensions and reinforcement details were the same in both models. In the design stage of the test models, the strong beam-weak columns were formed, as it is frequently observed in practice. A plan view of the reference structure is given in figure 1 and reinforcement details of the beams, columns and footings are given in figure 2 . All the columns and beams had dimensions of $200 \times 200 \mathrm{~mm}, 140 \times 200 \mathrm{~mm}$, respectively, and the footings had a cross section size of $600 \times 500 \mathrm{~mm}$. Such a stiff foundation has been designed to ensure fixed base conditions for the columns.

Covering concrete for all members were $20 \mathrm{~mm}$ thick. Columns were reinforced with four $6 \mathrm{~mm}$ plain bars longitudinally. Lateral reinforcement was provided by $6 \mathrm{~mm}$ stirrups with $100 \mathrm{~mm}$ spacing. In construction of the beams, four $8 \mathrm{~mm}$ plain bars were used. Lateral reinforcement scheme was the same as columns. Lateral reinforcement could not be finely-scaled as the smallest available bar size was $6 \mathrm{~mm}$. Beam-column joints and end regions of all elements were unconfined, having stirrups with $90^{\circ}$ hooks to simulate common practice. During the construction of experimental models, cold joints were formed and in order to observe sliding shear damage in the columns, longitudinal reinforcement ratio was kept limited. In the literature, many experimental studies on strengthening of $\mathrm{RC}$ frames without cold joints have tested 


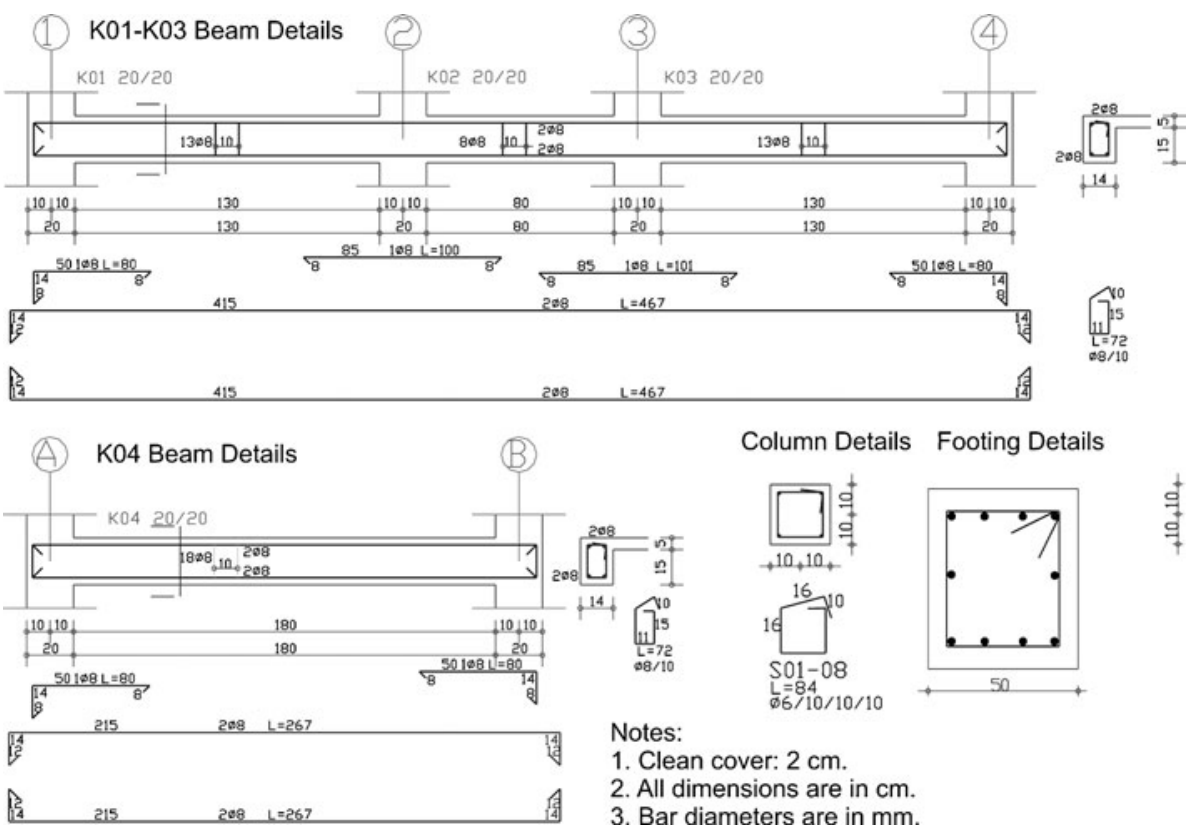

Figure 2. Reinforcement details for beams, columns and foundations.

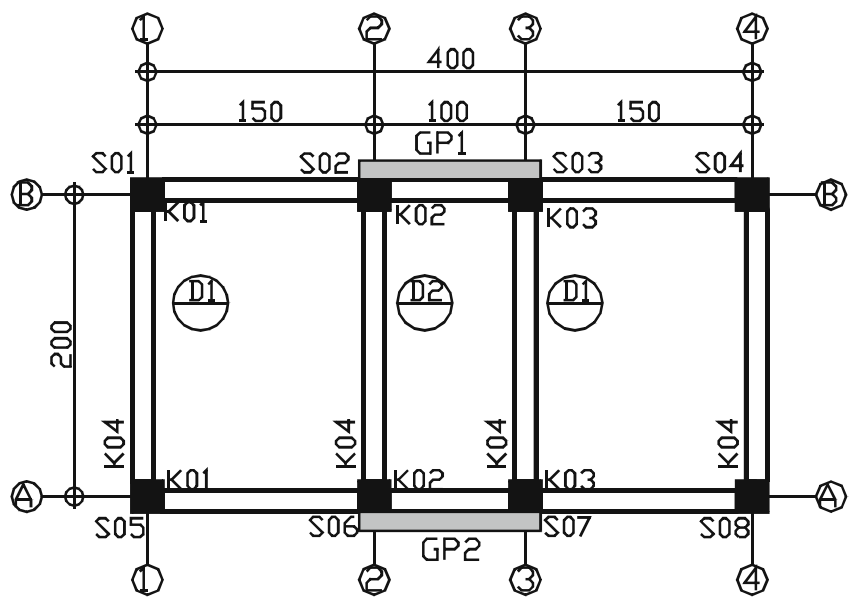

Figure 3. Plan view of strengthened structure (dimensions: $\mathrm{cm}$ ).

two-dimensional monolithic specimens (Altin et al 1992; Canbay et al 2003; Higashi et al 1982; Baran 2005; Kaltakci et al 2008). This study also makes a contribution about the effect of cold joint formations over the structural behaviour.

The plan view of strengthened structure is given in figure 3. Symmetrically placed shear walls were detailed according to specifications in the Turkish Earthquake Code (MPWS 2007) and ACI318 Code (ACI 2005). The new shear walls added to the system have been installed by taking the longitudinal load conditions into account. It is also possible to conduct this experiment 


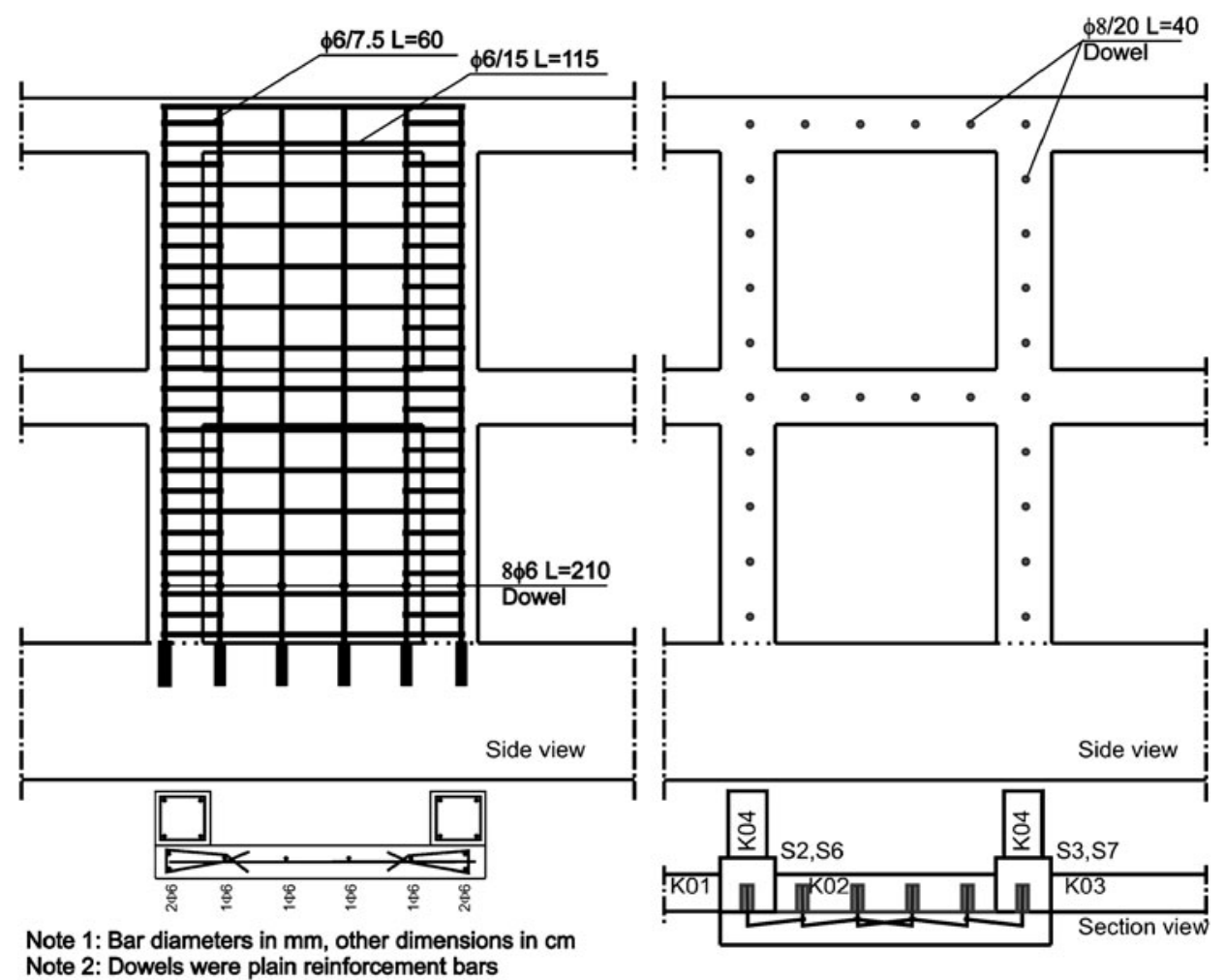

Note 2: Dowels were plain reinforcement bars Note 3: Epoxy resin was used for fixing dowels

Figure 4. Reinforcement and dowel details of the ESWs.

on a single frame, however, since the shear wall will be outside the axis, the experiment has been carried out on the three-dimensional model due to the risk of warping formation in the frame. The shear walls have been intentionally installed in the longitudinal direction to observe the shear walled frame behaviour in case of adding an exterior shear wall to the structure. The shear walls have been installed in a uniform direction since the loading was applied uniaxially, whereas in real life, buildings are subjected to seismic forces from every direction. Therefore, the shear walls should be implemented in both directions in real-life applications.

At the outset, the foundations of the test specimens were constructed. The possibility of causing damage to the specimens in case of moving them elsewhere has been considered since the total specimen weight would be in the order of $150 \mathrm{kN}$ and hence the test specimens were built on their foundations at the location of testing.

ESWs were connected to the model structure by dowels placed into the holes drilled in the faces of the beams and columns. Dowels were fixed into the old concrete by epoxy resin. Reinforcement used for dowels were $6 \mathrm{~mm}$ diameter plain bars. Dowels have been equidistantly installed onto the column and beam surfaces in contact with the exterior shear walls. Dowels had an anchorage depth of $100 \mathrm{~mm}$, where bond length inside the new ESW concrete was $300 \mathrm{~mm}$. Reinforcement and dowel details of the externally attached shear walls are shown in figure 4. Longitudinal reinforcements of the ESWs were anchored to the same continuous footing as the columns. 
Table 1. Concrete strength.

\begin{tabular}{lc}
\hline Storey/element & $\begin{array}{c}\text { Average concrete } \\
\text { strength (MPa) }\end{array}$ \\
\hline RM/First storey & 32.5 \\
RM/Second storey & 35.4 \\
SM/First storey & 31.8 \\
SM/Second storey & 31.3 \\
SM ESWs & 29.9 \\
\hline
\end{tabular}

Table 2. Strength of the reinforcement.

\begin{tabular}{lcc}
\hline Bar size & Yield strength (MPa) & Ultimate strength (MPa) \\
\hline ф6-bars & 328.3 & 398.7 \\
$\phi 8$-bars & 386.5 & 532.0 \\
\hline
\end{tabular}

For designing dowels that attach the ESWs to the existing structure, sliding shear capacity of the dowels were calculated according to ACI-318 (ACI 2005). The calculated capacity for dowels in the beam should be enough to transfer lateral loads at each floor onto shear walls. Also, dowels in the columns must have enough capacity so that the flexural yield in the shear wall is observed before any damage to the dowels occurs; i.e., couple force capacity provided by the column dowels must at least match the flexural capacity of the ESW.

The models were constructed at the test location to avoid any damage during transportation of the models. Concrete works have been discretely carried out for each storey to form cold joints. In order to obtain a homogeneous and good concrete, vibration has been applied by vibrators to the concrete. Curing is applied at all stages of the construction. No roughing process is applied to the beam and column surfaces connecting ESWs to the specimen. After construction of both stories, no construction work was performed during the following 28 days. Then, the dowels were fixed to the beam, the column and the footings. After the epoxy fill gained strength (5 days), ESWs were constructed at the last stage. Material strength of the concrete and steel used in experimental models are given in tables 1 and 2 respectively. Plain reinforcement bars were used for dowels.

\subsection{Experimental Set-up}

Elevation view of the experimental set-up is given in figure 5. The system consisted of the strong floor, reaction wall, actuator, actuator support, instrumentation, and finally the control and data acquisition systems. Instrumentation scheme of the specimens is given in figure 6 .

The specimens were instrumented with Linear Variable Differential Transformers (LVDTs) and Linear Position Transducers (LPT) for recording the storey displacements, ESW shear displacement, and the shear displacement in joints and curvatures of critical sections. Curvature measurements at the base of the ESW were taken from both the new ESW and the connecting columns to investigate monolithic behaviour.

Footings of the specimens were bolted to strong floor and reversed cyclic imposed sway was applied incrementally to the model structures to obtain their hysteretic behaviour. Lateral sway 


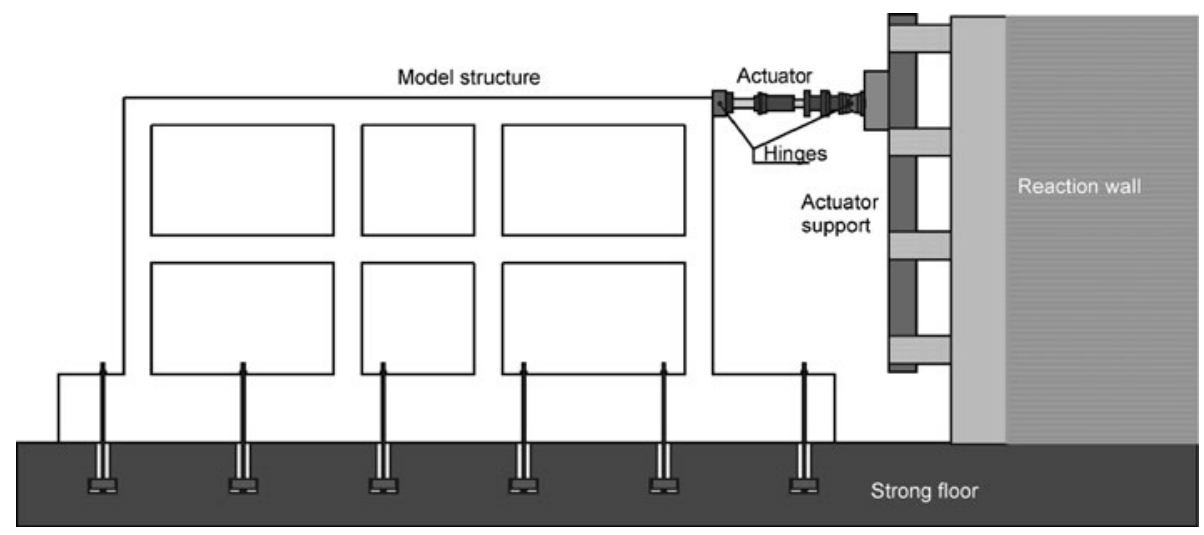

Figure 5. Experimental set-up.
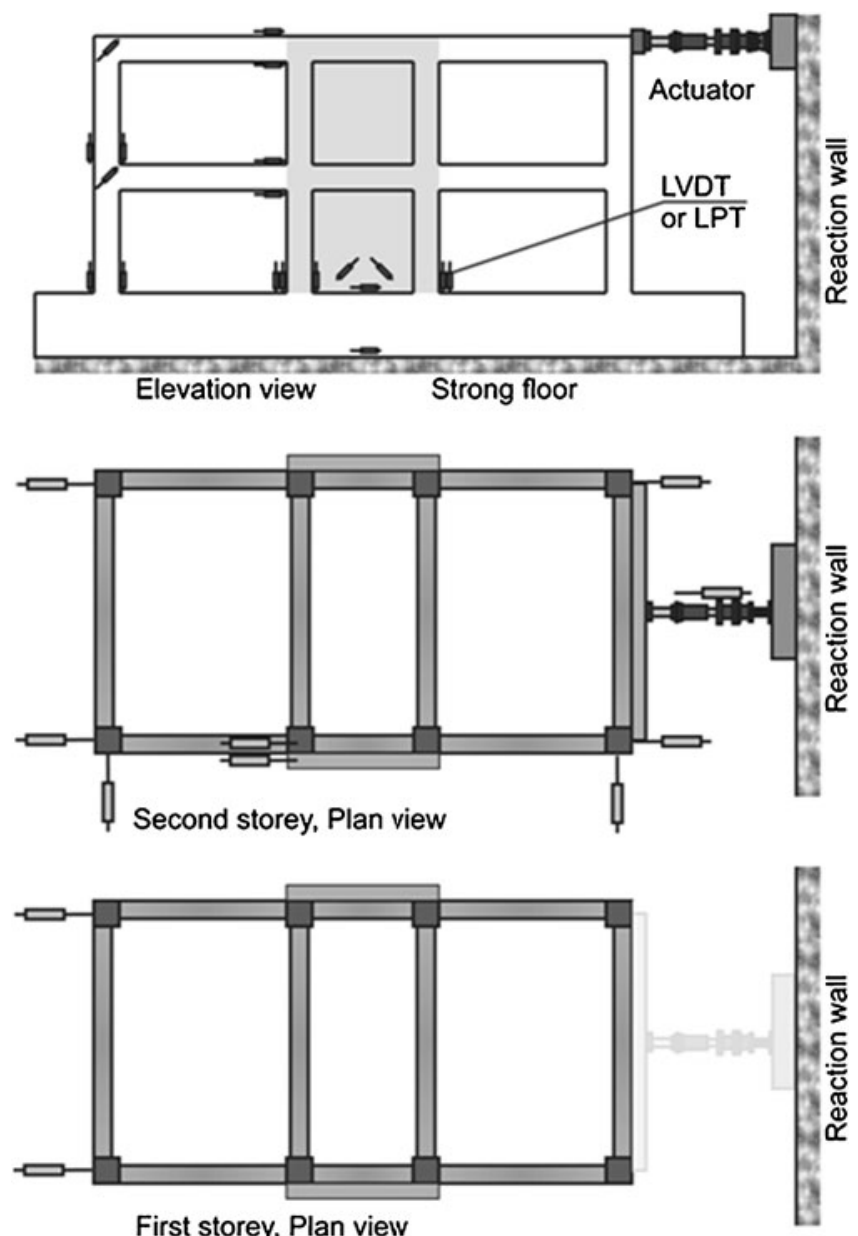

First storey, Plan view

Figure 6. Instrumentation of the specimens. 


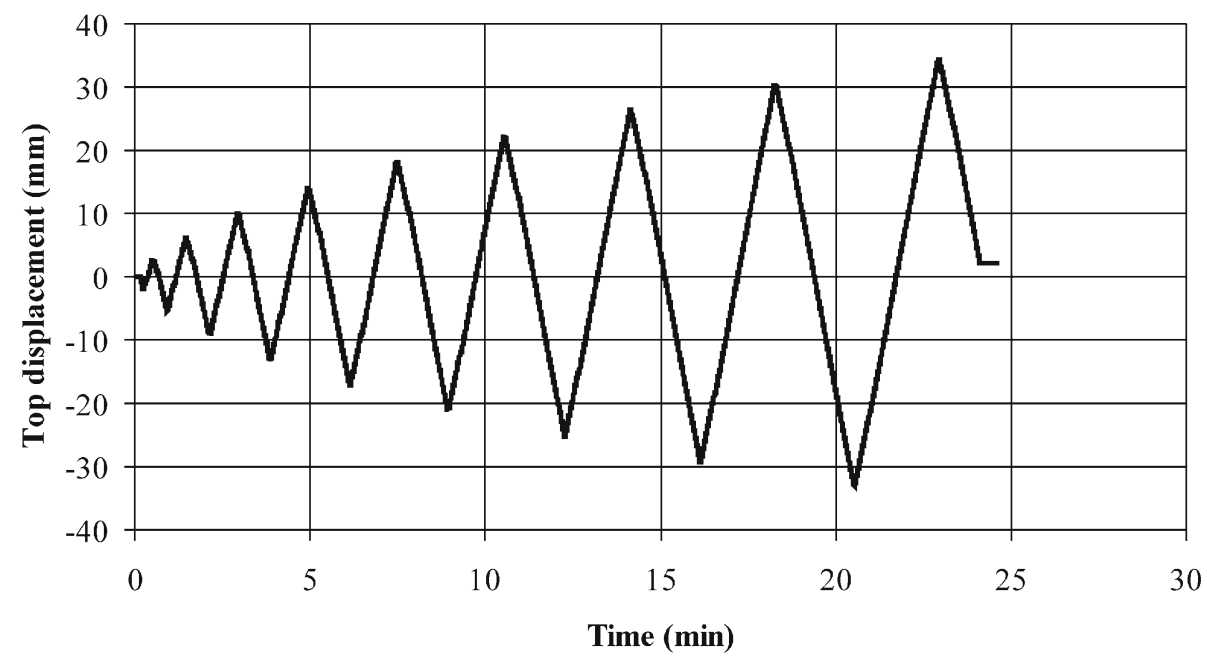

Figure 7. Imposed sway pattern on RM model.
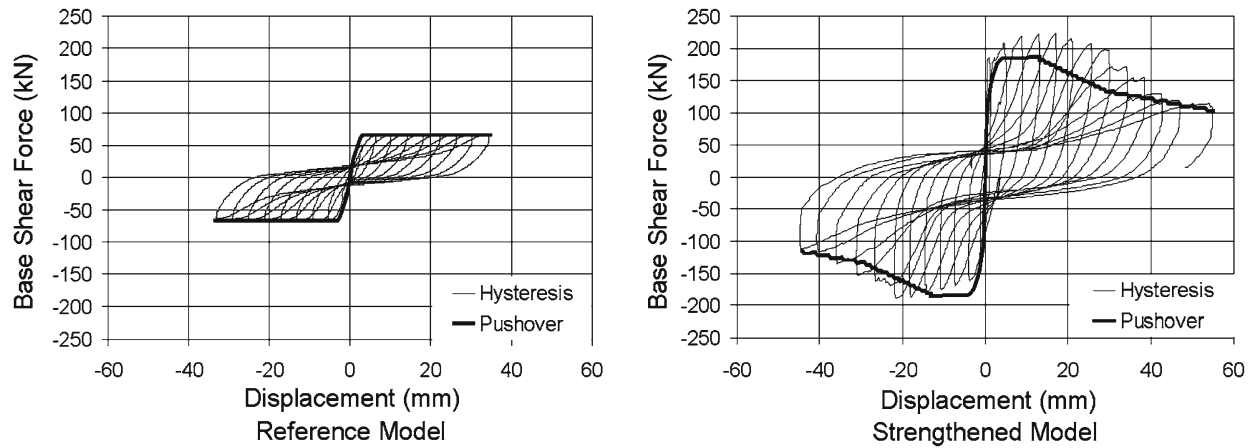

Figure 8. Hysteresis curves and analytical results for the reference and strengthened structure.

was applied to the top stories of the models. Sway pattern applied to the RM model is given figure 7.

\section{Experimental results}

After the experiments, hysteresis and pushover curves obtained for both models are shown in figure 8. Pinching behaviour was observed at both models during the experiments. Through the installation of new exterior shear walls to the model structure, a considerable increase in capacity and initial stiffness values have been obtained. For instance, the maximum lateral load capacity has increased to $223.5 \mathrm{kN}$ from $68.7 \mathrm{kN}$ and the initial stiffness of the system has increased 7-fold. A comparison of normalized lateral load capacities at various sway levels is presented in table 3 and changes in stiffness of the models are summarized in table 4.

The most important aspect of the application of the exterior shear walls is the connection between existing structural elements and the newly installed external shear wall. With two 
Table 3. Normalized experimental lateral loads.

\begin{tabular}{llcccc}
\hline Model & Stage & \multicolumn{3}{c}{ Normalized* lateral loads at various levels } \\
\cline { 3 - 6 } & & $\begin{array}{c}\text { Maximum } \\
\text { Load }\end{array}$ & $\begin{array}{c}\text { At 0.5\% } \\
\text { Drift }\end{array}$ & At 1\% Drift & $\begin{array}{c}\text { At 2\%** } \\
\text { Drift }\end{array}$ \\
\hline RM & Push & 1.00 & 1.00 & 1.00 & 0.99 \\
& Pull & 1.02 & 1.01 & 0.98 & 0.95 \\
& Average & 1.01 & 1.01 & 0.99 & 0.97 \\
SM & Push & 3.31 & 3.25 & 3.22 & 2.12 \\
& Pull & 2.81 & 2.59 & 2.80 & 1.75 \\
& Average & 3.06 & 2.92 & 3.01 & 1.94 \\
\hline
\end{tabular}

* 1 Unit normalized load corresponds to $67.5 \mathrm{kN}$

** As RM was not enforced to $2 \%$ drift, given normalized loads are belong to maximum drift for RM

Table 4. Initial lateral stiffness.

\begin{tabular}{lcc}
\hline Model & Initial stiffness $(\mathrm{kN} / \mathrm{mm})$ & Normalized stiffness \\
\hline $\mathrm{RM}$ & 25.12 & 1.00 \\
$\mathrm{SM}$ & 181.39 & 7.22 \\
\hline
\end{tabular}

existing columns, the new wall has a $\mathrm{C}$ type cross section. When the walls and the columns could be made to behave like a monolithic element, then it can be said that the method has been successful. Curvature at the bottom of the wall is measured from the ultimate tension and compression fibres of the $\mathrm{C}$ section. Curvature measurements of the fibres of the new wall and existing columns have been compared with the lateral top displacements of the wall and columns in figure 9. As shown in the figure, during the first 16 cycles, curvature measurements from the column faces and wall faces were the same. After this step, sliding of the wall base occurred and due to local damages, some errors were reflected in the measurements. On the other hand, top measurements were the same throughout the experiment. Therefore, it is possible to conclude that new walls and connected columns behaved like a monolithic single structural element.

Behaviour of the new shear wall as a singular element with the connecting column is given in figure 10. A similar level of damage was observed in the similar fibre levels of the old and new concrete of composite shear wall section. During the compression cycle, both covers of the wall and the facing column were crushed; whereas, due to the acting tensile stresses, columns behave as the end region of the shear wall cross section, which results in fracturing of longitudinal bars inside them.

General view of the damaged SM after the experiment is shown in figure 11. The model had no stability problems, although its lateral load capacity deteriorated significantly.

Cracking patterns observed during the experiments and damage levels obtained by pushover analysis are compared in figure 12. The cracking was observed in the column ends at RM model. In the cold joints, which are built at the bottom of the columns during construction, sliding shear behaviour also took place. However, in the SM model, beams connected to shear walls suffered some damage. Since lightly reinforced weak columns were employed, no cracking was formed at beam ends that were connected to the columns. Most importantly, the first occurrence of 

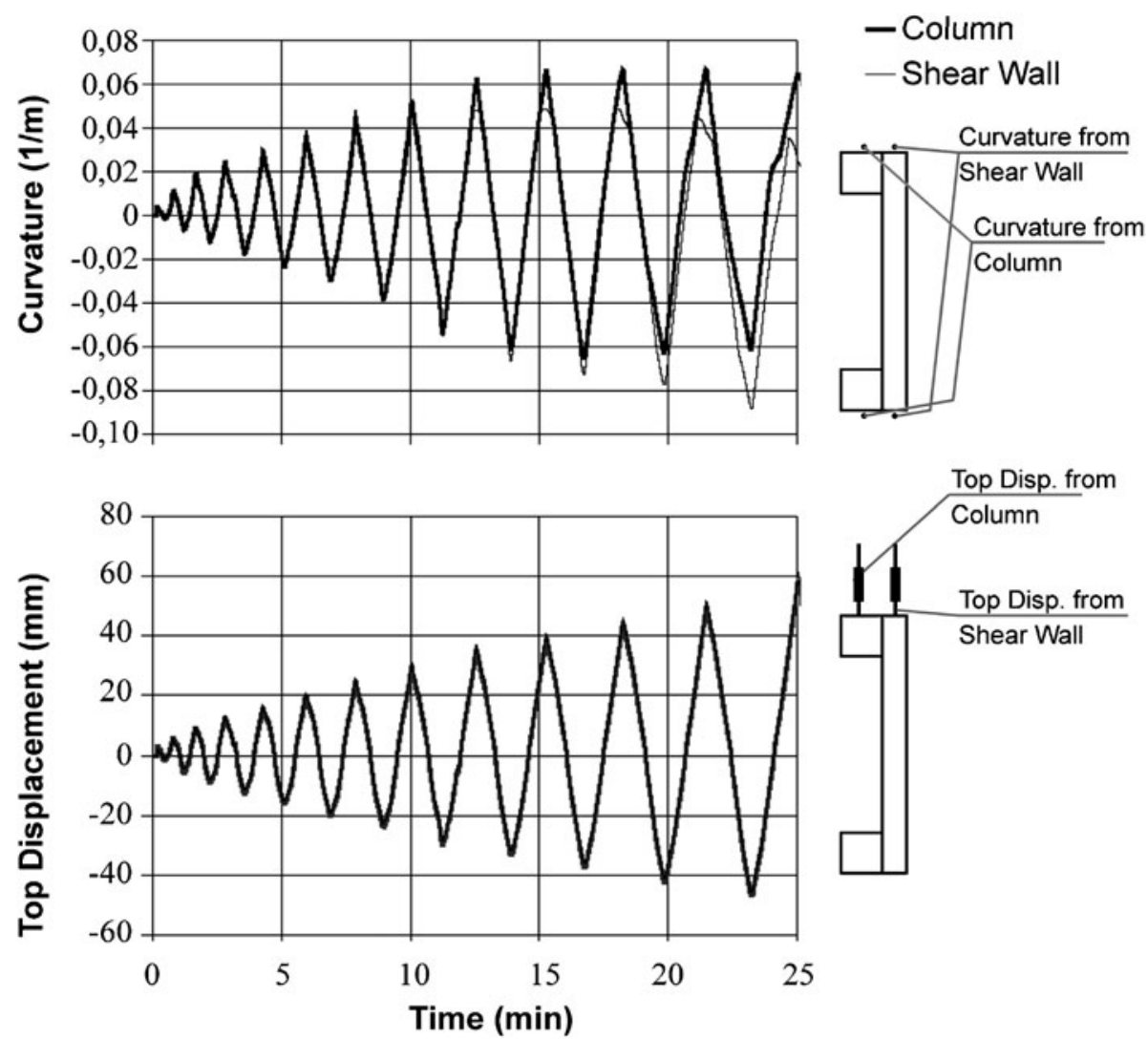

Figure 9. Measured curvature and top displacement of the shear walls measured from wall and connected column.

cracking in the strengthened model was observed at the bottom of the shear walls. Afterwards, due to rupturing of some of the longitudinal steel bars in the shear walls, sliding shear capacity of the walls significantly decreased and sliding behaviour at the base of the shear walls was observed. For both RM and SM, the system obviously displayed no torsional response and the right and left frames behaved similarly.

\section{Numerical study}

\subsection{Modelling approach}

The analysis of the models used in the experiments has been performed by SAP2000 V8, generalpurpose structural analysis software (CSI 2002), which is able to carry out nonlinear pushover analysis as well, has been used in the study.

For the nonlinear analysis, both the reference and strengthened experimental structures have been modelled by SAP2000 in three-dimensions. The column and beam elements have been modelled as frame elements and the shear walls have been modelled in reference to the wide column approach. The columns to which the shear wall elements were attached have not been 


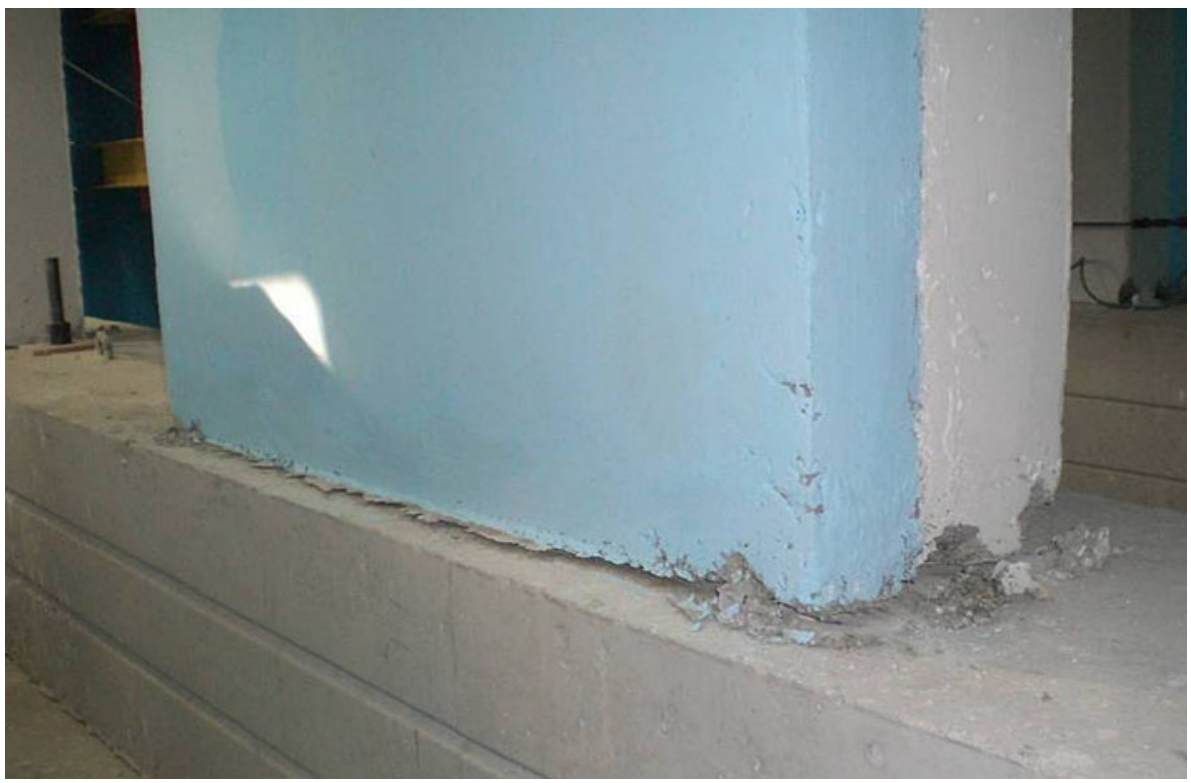

Figure 10. Concordant behaviour of the connecting column and the new shear wall.

modelled separately; rather, they have been considered to be inside the shear wall cross section. Then, the shear wall and the columns on both ends were modelled as a single frame element. In all of the models, the foundations were not included in the structural model and bottom ends of the columns and the shear walls were modelled as fixed based.

The column and beam elements have been modelled with plastic hinges so that lumped plasticity behaviour would be observed on their ends. The allocation of plastic hinges on the frames along the loading direction (longitudinal side of the building) has been presented in figure 13 . The same hinge properties were assigned to similar frame elements. The plastic hinge behaviour in SAP2000 has been defined by idealized multilinear models. The load-displacement relationship of the plastic hinges is defined by the 5 data points named A, B, C, D and E shown in figure 14. The load and displacement values assigned to these points which determine the nonlinear behaviour varies with the quality of the material used in the cross section, the reinforcement details and the axial load on the element.

The effective stiffness of the column, beam and shear elements was taken to be equal to $40 \%$ of gross stiffness. Since a live load on the experimental specimen does not exist, no such vertical loading has been enacted in the SAP2000 model.

It has been stated that due to the capability of defining default plastic hinges, the SAP2000 default hinges defined in previous studies can be used in structures in compliance with modern codes. However, it is also recommended that the user defines the hinge properties either by conducting moment-curvature analysis for older structures or employing the deformation capacities given in FEMA 356 (2000) to achieve more accurate results (Inel \& Ozmen 2006). For this reason, the plastic hinge moment capacity for each critical cross section has been defined by conducting moment-curvature analyses. Regarding the moment-curvature analyses, it has been assumed that the axial force in the columns remains fixed, whereas it is assumed to be zero at the beams. The Hognestad model (Hognestad 1951) for covering concrete, the Mander model for confined concrete (Mander et al 1988) and the typical stress- 


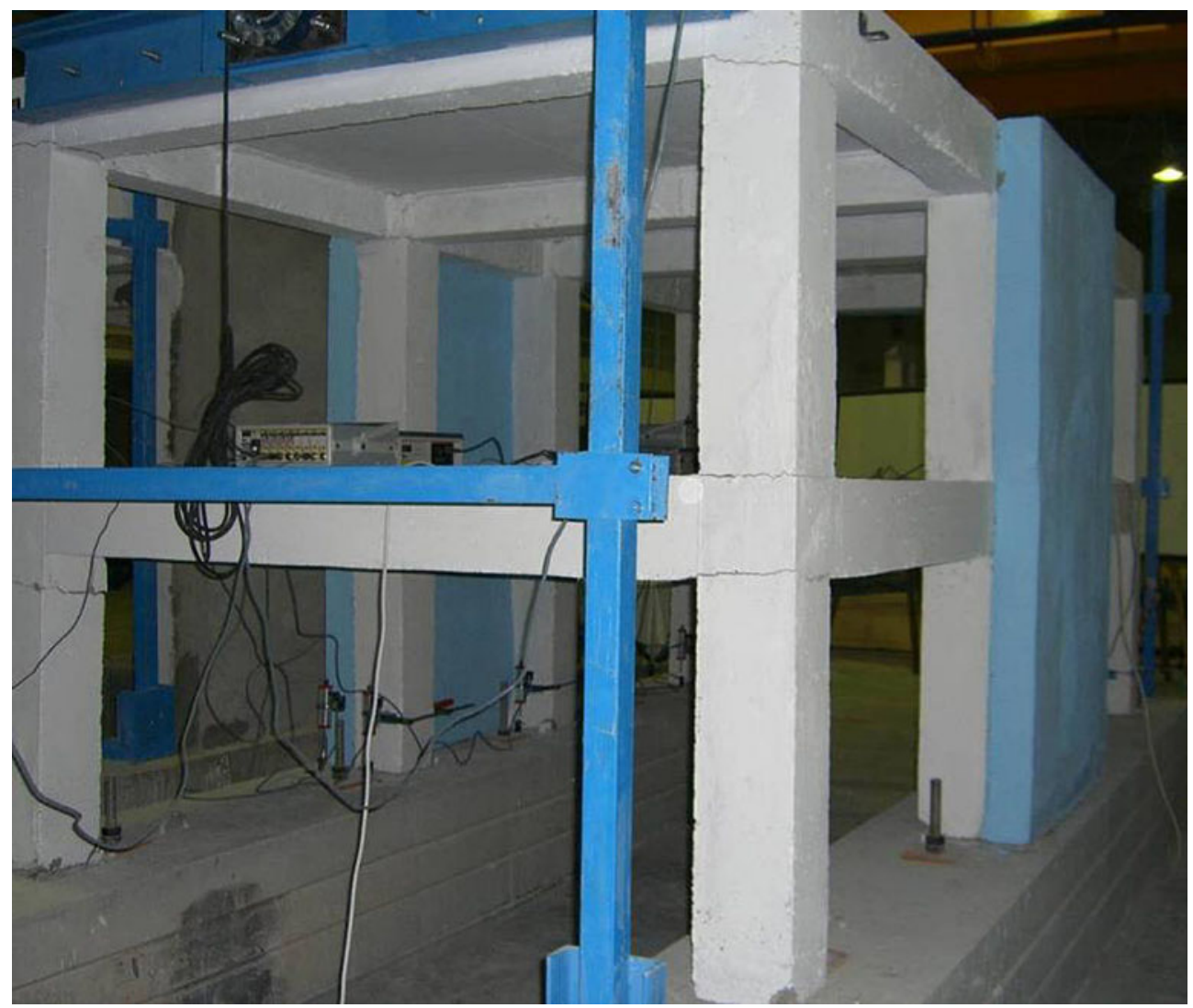

Figure 11. Damaged SM after the test.
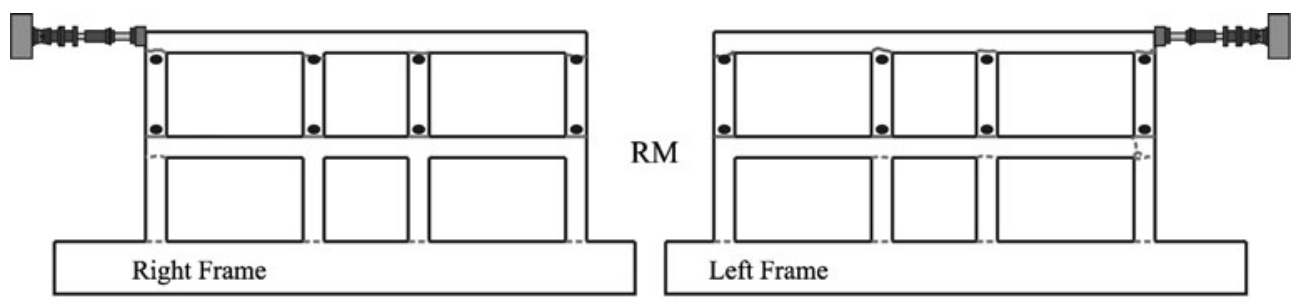

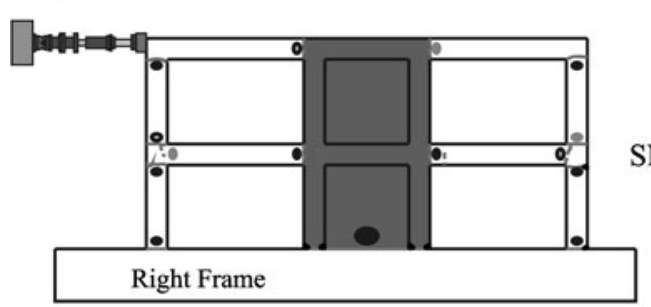

Damages (Numerical model)

- Plastic hinge (push \& pull)

- Plastic hinge (push)

- Plastic hinge (pull)

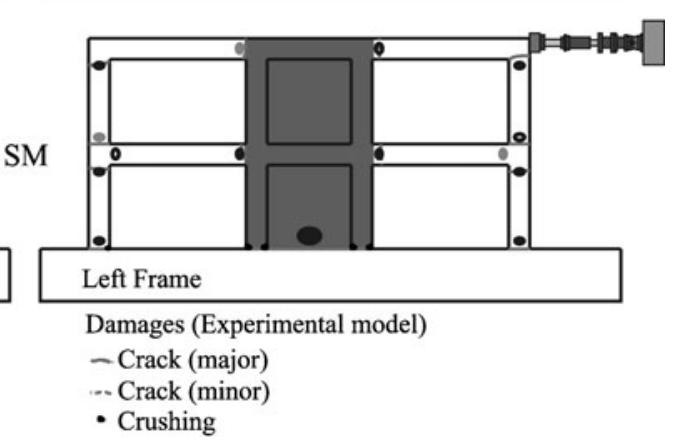

Figure 12. Cracking pattern of RM and SM. 

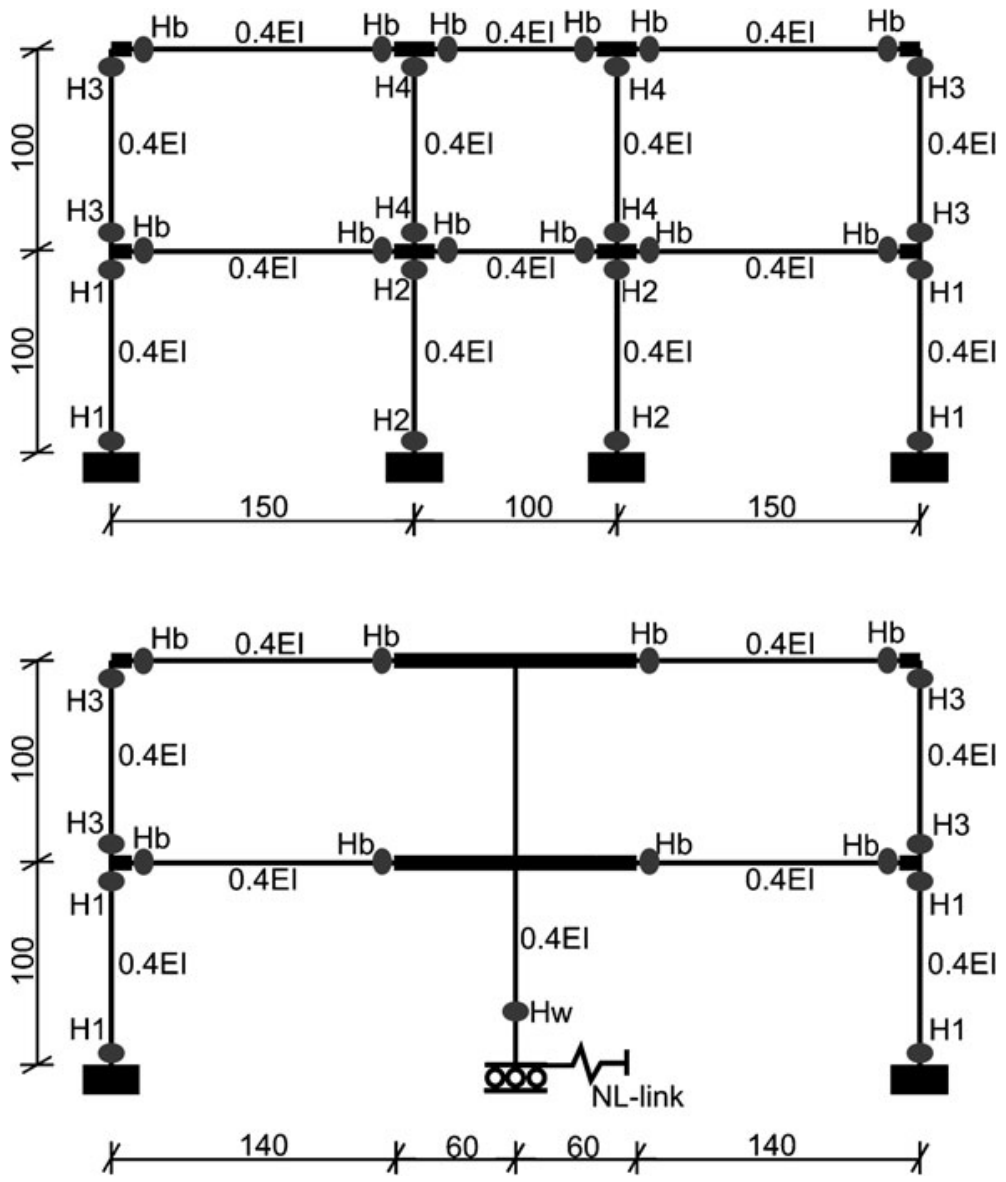

Figure 13. Model parameters and distribution of plastic hinges in RM and SM.

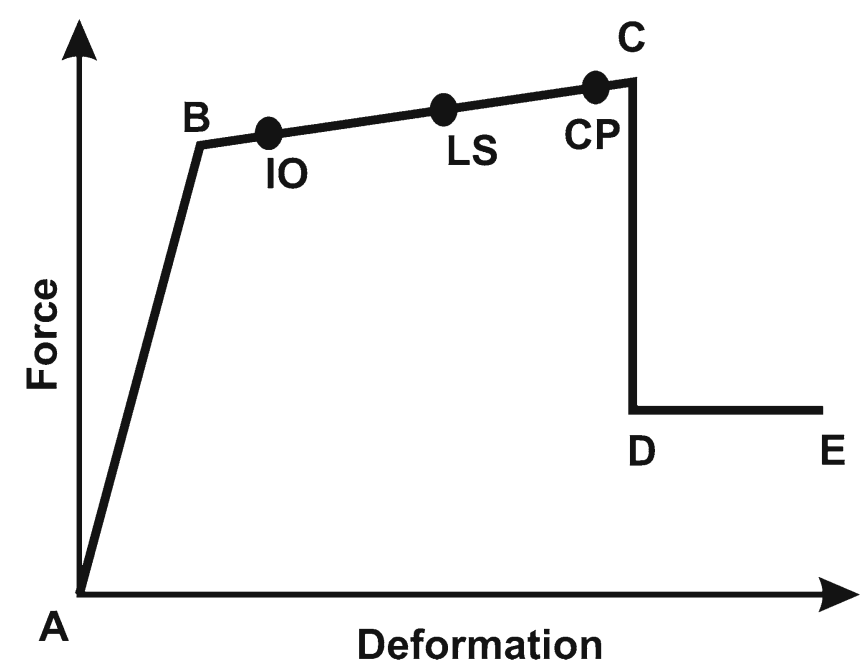

Figure 14. Typical plastic hinge model used in SAP2000. 


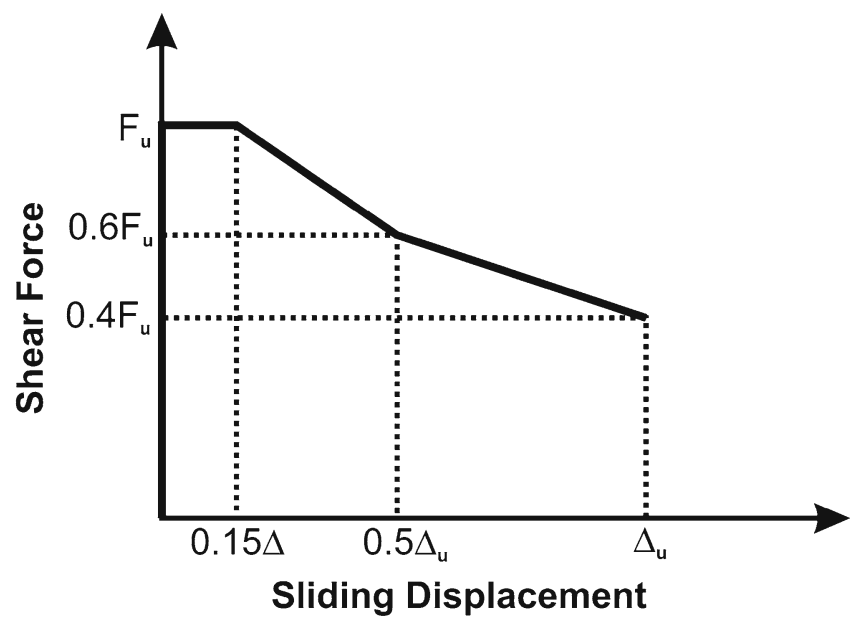

Figure 15. Base shear-displacement model for sliding shear of ESWs.

strain model with strain hardening (Mander 1984) for steels have been utilized. Deformation limits of the elements have been determined as per FEMA 356 (2000). The effects of insufficient anchor and overlapping lengths over the capacity have been calculated in accordance with FEMA 356 (2000) and the necessary capacity reductions were carried out.

Since the flexural plastic hinges can be defined based on moment-rotation relationship in SAP2000, moment-curvature relationship has been converted to moment-rotation relationship. In this conversion, the plastic hinge length $L_{p}$ has been taken to be half of the cross section depth (H) as presented in Eq. 1 (Moehle 1992).

$$
L_{p}=0.5 H
$$

To account the sliding shear behaviour at the base of shear walls, nonlinear link (NL-link) elements have been employed. Shear capacities of these elements have been calculated by considering the safety coefficients given for sliding shear as well (Bass et al 1989). The nonlinear sliding shear model utilized in the analyses is shown in figure 15.

\subsection{Comparison of numerical and experimental results}

Comparison of the hysteretic behaviour and nonlinear pushover curves are given in figure 8 . The numerical and experimental results showed reasonable correlation with each other.

The experimental and numerical damage patterns were compared for the RM and SM in figure 12. In the RM model, the damage was concentrated at second storey columns. Minor cracks were observed at the bottom of first storey columns due to cold joints. The plastic hinge locations were successfully determined by the numerical models. As previous studies showed that $20 \%$ differences can be obtained for identical RC models (Harris \& Sabnis 1999), the capacity curve estimations were reasonable on average. However, minor cracks in cold joints cannot be identified by numerical analysis as the section yield capacity was not reached. Regarding the SM model, the numerical model perfectly identified the sliding shear behaviour at the bottom of the shear wall. After sliding, the damage was concentrated at the first floor of the structural system, which was also similarly observed in the numerical model. 
Table 5. Comparison of experimental and analytical loads at various drift levels.

\begin{tabular}{llccc}
\hline Model & Comparison point & $\begin{array}{c}\text { Experimental } \\
\text { load }(\mathrm{kN})\end{array}$ & $\begin{array}{c}\text { Analytical } \\
\text { load }(\mathrm{kN})\end{array}$ & $\begin{array}{c}\text { Experimental } \\
\text { / analytical }\end{array}$ \\
\hline RM & Maximum Load & 68.10 & 66.30 & 1.027 \\
& At 0.5\% Drift & 67.95 & 66.20 & 1.026 \\
& At 1\% Drift & 66.75 & 66.30 & 1.007 \\
& At 2\% Drift & - & 47.30 & - \\
SM & Maximum Load & 206.60 & 184.50 & 1.120 \\
& At 0.5\% Drift & 197.20 & 184.40 & 1.069 \\
& At 1\% Drift & 202.95 & 168.80 & 1.202 \\
& At 2\% Drift & 130.75 & 123.70 & 1.057 \\
\hline
\end{tabular}

* Average of push and pull stages

It is important to note that plastic hinge formations could be missed by pushover analysis carried out in one direction. During the pushover analysis of the SM, push and pull directions generated different plastic hinge distributions. However, combination of the two pushover cases yielded better results.

Experimental and numerical lateral loads have been compared at various drift levels in table 5. Maximum level of errors is approximately 3\% and 20\% for RM and SM models, respectively. Error level in SM is quite higher, but this is only due to the different starting point of sliding behaviour at ESWs. In the numerical model, sliding behaviour starts earlier than it does in the experimental model. Therefore, the maximum level of error increases in the SM model.

\section{Conclusions}

In this study, an experimental investigation on seismic strengthening of the RC buildings by exterior shear walls has been carried out. Structures of the two storey framed model were tested under the imposed reversed cyclic lateral sway to simulate seismic loadings. It is observed that the implementation of shear walls to the structural system has improved the capacity of the bare frame as expected. Main conclusions of the study are as follows:

(i) It was observed and measured that the newly added external shear wall and the connected end columns and beams behave like a monolithic member. Minor cracks between new and existing elements have been formed after $1 \%$ drift. Even after these minor cracks, the shear walls did not lose their load bearing capacity.

(ii) The first cracking occurred at the bottom of the exterior shear walls due to bending in initial stages of the experiment. During the subsequent cycles, sliding shear capacity of the shear walls drooped due to the rupturing of the longitudinal bars and in addition, shear sliding behaviour was observed at the bottom of the walls. This had an adverse effect on ductility and energy absorption capacity of the system. To prevent such damage, additional shear reinforcement is required at the web of the wall.

(iii) In order to test the behaviour without any overstrength of dowel capacity, no material factor was considered in the design process and experimental yield strength values were used instead of characteristic yield strength. For designing the dowels, ACI318 (ACI 2005) 
shear friction formulae were used. Although the dowels possessed no overstrength, they adequately transferred the loads between existing and new elements safely. Therefore, the shear friction formula can be used for designing the connection of exterior shear wall with existing structural elements.

(iv) Response modification factor ( $\mathrm{R}$ ) is an important parameter for the seismic design of buildings. In the experimental study, the strengthened model reached yield strength at about 4-5 $\mathrm{mm}$ roof displacement, where the base shear capacity started to fall after $23 \mathrm{~mm}$ of roof displacement. Therefore, a response modification factor of 4 to 5 can be used for ESW strengthened buildings to determine the design force demand for the ESWs.

(v) Results obtained from the experimental models were close to numerical results. In this regard, it has been proven again that with the correct structural model, it is possible to create a successful design for strengthening the existing structures. However, further studies are needed to develop sliding shear models for nonlinear analyses of shear walled structures. In the present work, sliding shear capacity was calculated based on the code formulations, which produced a smaller capacity than the actual base shear capacity. Besides, it is found out that composite cross sections of the dowel-bonded exterior shear walls and the existing column elements can be modelled as a single frame element using wide column analogy. This behaviour has been observed experimentally and numerical solutions yielded reasonable results.

(vi) The strengthened model is a symmetric structure and therefore, uniform strengthening walls were used. Application of the proposed technique to asymmetric buildings requires a carefully performed design to minimize the effects of torsional loads by minimizing the eccentricity, which can be compensated by an appropriate arrangement of the new shear walls. Since the model used in this study was loaded uniaxially, it was strengthened with respect to that direction only. However, existing seismically deficient buildings are vulnerable to seismic forces from any direction. Therefore, buildings must be strengthened at right angles in real-life applications of exterior shear walls.

(vii) The technique has been tested on an undamaged model. However, the existing literature presents many techniques for the reparation of damaged buildings and similarly, this method can also be used for strengthening damaged buildings. In this case, the designer should keep in mind the possibility of a significant decrease in stiffness and the capacities of previously damaged elements, and consider that the level of the damage may significantly affect the cost of strengthening works. Consequently, strengthening of damaged buildings by exterior shear walls is an important topic for future researches.

(viii) Addition of shear walls to a structure will definitely improve its lateral load capacity. This fact has been demonstrated by many experimental studies carried out for infill strengthening walls. However, an infill wall with poorly designed dowels can even improve strength performance considerably by providing bracing effect. On the other hand, exterior shear walls cannot improve the capacity in case of dowel failure. The key point of this study is that exterior shear walls can be successfully applied to existing vulnerable buildings to improve seismic capacity provided that the dowels are well-designed.

This study has been carried out with the financial support of State Planning Organization of Turkey with grant number BAP-08-11-DPT.2004K120760, with Middle East Technical University (METU) coordination, and Pamukkale University with grant number PAUBAP2006FBE020. This support is gratefully acknowledged. 


\section{References}

ACI Committee 3182005 Building code requirements for structural concrete and commentary (ACI 318M05). American Concrete Institute

Albanesi T, Biondi S, Candigliota E and Nuti C 2006 Experimental analysis on a regular full scale infilled frame. Proceedings of the First European Conference on Earthquake Engineering and Seismology, Geneva, Paper No. 1608

Altın S, Ersoy U and Tankut T 1992 Hysteretic response of reinforce concrete infilled frames. ASCE J. Struct. Eng., 118(8): 2133-2150

Baran M 2005 Precast concrete panel infill walls for seismic strengthening of reinforced concrete framed structures. PhD thesis, Middle East Technical University, Ankara

Bass R A, Carrasquilloi R L and Jirsa J O 1989 Shear transfer across new and existing concrete interfaces. ACI Struct. J., 86(4): 383-393

Bush T D, Wyllie L A and Jirsa J O 1991 Observations on two seismic strengthening schemes for concrete frames. Earth. Spectra, 7(4): 511-527

Canbay E, Ersoy U and Ozcebe G 2003 Contribution of reinforced concrete infills to seismic behaviour of structural systems. ACI Struct. J., 100(5): 637-643

CSI, SAP2000 V-8 2002 Integrated finite element analysis and design of structures basic analysis reference manual. Berkeley, California (USA): Computers and Structures Inc.

Federal Emergency Management Agency, FEMA-356 2000 Prestandard and commentary for seismic rehabilitation of buildings. Washington (DC)

Frosch R J, Wanzhi L, Jirsa J O and Kreger M E 1996 Retrofit of non-ductile moment-resisting frames using precast infill wall panels. Earth. Spectra, 12(4): 741-760

Gilmore A T, Bertero V V and Youssef N F G 1996 Seismic rehabilitation of infilled non-ductile frame buildings using post-tensioned steel braces. Earth. Spectra, 12(4): 863-882

Harris H G and Sabnis G M 1999 Structural modeling and experimental techniques. 2nd ed, Florida: CRC Press Inc

Higashi Y, Endo T and Shimizu Y 1982 Effects on behaviours of reinforced concrete frames by adding shear walls. Proceedings of the Third Seminar on Repair and Retrofit of Structures, Michigan, pp. 265290

Hognestad E A (1951) Study of combined bending and axial load in RC Members Engineering Experimental Station Bulletin Series No. 399, University of Illinois

Inel M and Ozmen H B 2006 Effects of plastic hinge properties in nonlinear analysis of reinforced concrete buildings. Eng. Struct., 28(11): 1494-1502

Jirsa J and Kreger M 1989 Recent research on repair and strengthening of reinforced concrete structures. Proceedings of the ASCE Structures Congress, California, 1: 679-688

Kaplan H, Yılmaz S, Cetinkaya N, Nohutcu H and Atımtay E Gönen H (2009) A new method for strengthening of precast industrial structures. J. of the Faculty of Eng. and Archit. of Gazi Univ., 24(4): 659-665, (in Turkish)

Kaltakci M Y, Arslan M H, Yilmaz U S and Arslan H D 2008 A new approach on the strengthening of primary school buildings in Turkey: An application of external shear wall. Build. and Environ., 43(6): 983-990.

Mander J B 1984 Seismic design of bridge piers. Research report 84-2, Christchurch (New Zealand), Department of Civil Engineering, University of Canterbury

Mander J B, Priestley M J N and Park R 1988 Theoretical stress-strain model for confined concrete. ASCE J. Struct. Eng., 114(8): 1804-1826

Masri A and Goel S 1996 Seismic design and testing of an RC slab-column frame strengthened with steel bracing. Earth. Spectra, 12(4): 645-666

Ministry of Public Works and Settlement 2007 Turkish Earthquake Code-2007. Specifications for buildings to be built in seismic areas. Ankara, Turkey (in Turkish)

Moehle J P 1992 Displacement-based design of RC structures subjected to earthquakes. Earth. Spectra, 8(3): 403-428 
Moehle J P 2000 State of research on seismic retrofit of concrete building structures in the US. Proceeding of US-Japan symposium and workshop on seismic retrofit of concrete structures - State of Research and Practice, USA

Ohmura T, Hayashi S, Kanata K and Fujimura T 2006 Seismic retrofit of reinforced concrete frames by steel braces using no anchors. Proceedings Of The 8th National Conference On Earthquake Engineering. California

Perera R, Gómez S and Alarcón E 2004 Experimental and analytical study of masonry infill reinforced concrete frames retrofitted with steel braces. ASCE J. Struct. Eng., 130(12): 2032-2039

Sonuvar M O, Ozcebe G and Ersoy U 2004 Rehabilitation of reinforced concrete frames with reinforced concrete infills. ACI Struct. J., 101(4): 494-500

Sucuoglu H, Jury R, Ozmen A, Hopkins D and Ozcebe G 2006 Developing retrofit solutions for the residential building stocks in Istanbul. Proceedings of 100th Anniversary Earthquake Conference, California

Yakut A, Gülkan P, Bakır B S, Yılmaz M T 2005 Re-examination of damage distribution in Adapazarı structural considerations. Eng. Struct., 27(7): 990-1001 